\title{
Chronic occupational exposures can influence the rate of PTSD and depressive disorders in first responders and military personnel
}

\author{
Anthony Walker ${ }^{1,2^{*}}\left(\mathbb{D}\right.$, Andrew McKune ${ }^{1,3}$, Sally Ferguson ${ }^{4}$, David B. Pyne ${ }^{2,5}$ and Ben Rattray ${ }^{2,3}$
}

\begin{abstract}
Background: First responders and military personnel experience rates of post-traumatic stress disorder (PTSD) far in excess of the general population. Although exposure to acute traumatic events plays a role in the genesis of these disorders, in this review, we present an argument that the occupational and environmental conditions where these workers operate are also likely contributors.

Presentation of the hypothesis: First responders and military personnel face occupational exposures that have been associated with altered immune and inflammatory activity. In turn, these physiological responses are linked to altered moods and feelings of well-being which may provide priming conditions that compromise individual resilience, and increase the risk of PTSD and depression when subsequently exposed to acute traumatic events. These exposures include heat, smoke, and sleep restriction, and physical injury often alongside heavy physical exertion. Provided the stimulus is sufficient, these exposures have been linked to inflammatory activity and modification of the hypothalamic-pituitary axis (HPA), offering a mechanism for the high rates of PTSD and depressive disorders in these occupations.

Testing the hypothesis: To test this hypothesis in the future, a case-control approach is suggested that compares individuals with PTSD or depressive disorders with healthy colleagues in a retrospective framework. This approach should characterise the relationships between altered immune and inflammatory activity and health outcomes. Wearable technology, surveys, and formal experimentation in the field will add useful data to these investigations.

Implications of the hypothesis: Inflammatory changes, linked with occupational exposures in first responders and military personnel, would highlight the need for a risk management approach to work places. Risk management strategies could focus on reducing exposure, ensuring recovery, and increasing resilience to these risk contributors to minimise the rates of PTSD and depressive disorders in vulnerable occupations.
\end{abstract}

Keywords: Cytokines, IL-6, Mood disorders, Firefighters, Military, Inflammation, Sickness behaviour

\section{Background}

First responders and military personnel work in physically demanding settings characterised by traumatic events and personal danger, often coupled with

\footnotetext{
*Correspondence: Anthony.walker@canberra.edu.au

1 University of Canberra Research Institute for Sport and Exercise,

University of Canberra, Canberra, Australia

Full list of author information is available at the end of the article
}

environmental and occupational stressors. Possibly, as a consequence of ongoing exposure to traumatic events, first responders and military personnel experience relatively high levels of depression and post-traumatic stress disorder (PTSD) $[1,2]$. These outcomes can be initiated by exposure to a range of internal and external cues, and are often characterised by avoidance and periods of hyper arousal [3]. Currently, most treatment programs for PTSD focus on the response to sudden traumatic 
events. However, it is unclear whether acute exposure to traumatic events is the sole reason for the high prevalence of depression and PTSD in first responders and military personnel. While research efforts have generally focussed on increasing psychological resilience, the underlying physiological mechanisms that predispose individuals to developing depressive disorders or PTSD remain unclear. In this review, we examine possible links between occupational exposures to heat and smoke, sleep restriction, and chronic physical stress that could predispose emergency and military personnel to depression or PTSD.

Exposure to maimed or fatally injured persons is recognised as a substantial contributor to increased prevalence of health care utilisation and mental health care access by first responders [4] and military personnel. Specifically, exposure to acute traumatic events is associated with $\sim 13-18 \%$ of first responders experiencing PTSD following events, such as large-scale emergencies [1], terrorist attacks $[5,6]$, natural disasters $[7,8]$, and industrial accidents $[2,9]$. Unlike the general population, many first responders and military personnel will be exposed to traumatic events numerous times during their career. Thus, possibly, as a result of multiple exposures, lifetime prevalence of PTSD in first responders can be as high as $32 \%$ [2], compared with estimates in the general population of $6-14 \%$ [1].

Not all first responders or military personnel experience PTSD after exposure to stressful events $[10,11]$. For example, despite similar exposure to war casualties, US army medics returning from Iraq displayed lower rates of PTSD or depression than soldiers [1]. Medics reported frequent exposure to combat (28\%), to injured or dead friendly forces (62\%), perceptions of personal danger (38\%), and potential death (23\%), all which are psychological stressors. Although this incidence (20-60\%) compares with up to $90 \%$ of soldiers reporting frequent combat exposure [12], the higher rates of depressive disorders in soldiers appear disproportionally high given that medics are $\sim 17$ times less likely to develop symptoms of PTSD than soldiers in the same theatre of battle [12]. It may also be that those individuals self-selecting to fulfil the role of medics may be more psychologically resilient than soldiers. Regardless, a clear differentiation between soldiers and medics in the operational requirements of their roles, in particular the exposure to environmental conditions and physical exertion and trauma, likely occurs. Thus, it appears that exposure to traumatic events may not be solely responsible for the rates of PTSD and depression in military or first responder populations, and other environmental or physiological factors might mediate the increased risk of these disorders.

\section{Presentation of the hypothesis}

Although depression and PTSD are complex multi-faceted conditions or perhaps, set of conditions, inflammation plays a role in many depressive states. Both acute bouts of inflammation, as well as chronic low-grade inflammation, have been linked to depressive states, and in vulnerable individuals, the reduction of inflammation is likely to improve psychological and general well-being. First responders and military personnel are regularly exposed to environmental and occupational stressors that present as pro-inflammatory stimuli. Thus, we propose that these exposures provide a priming stimulus (Fig. 1), which predisposes individual workers to a higher risk of depressive disorders following acute traumatic events.

\section{Pathophysiology of depression}

\section{Sickness behaviours}

Sickness behaviours are common responses observed during periods of illness and injury. Sickness behaviour was originally described in ill animals with reduced activity and sleep, feeding, and grooming and social interactions [13] akin to signs of depression [14]. This grouping of behaviours is believed to have been conserved throughout evolution $[13,15]$ most likely as a generalised adaptation to infection and injury. It makes sense that the body has a built-in signal to alter behaviour and conserve energy when under stress, preserving available resources and energy to heal. These behaviours are not merely reflexive reactions to "illness" either, but represent a central motivational state [16], that assists the organism in recovery, and potentially protects others in the group [17].

\section{Inflammation}

It was long believed that the blood-brain barrier (BBB) provided an impenetrable barrier to protect the brain and wider central nervous system (CNS) from systemic molecules that are potentially damaging or responsible for behaviour change. However, more recent evidence indicates that acute or chronically elevated levels of circulating cytokines can cross the BBB through a variety of mechanisms [18] and signal the brain via both direct and indirect pathways. This communication can lead to neural and associated behaviour changes, such as feelings of tiredness and reduced motivation [19]. Dantzer and colleagues [19] proposed that systemic low-grade inflammation, typically defined by a two- to three-fold increase in plasma concentrations of pro-inflammatory cytokines, such as interleukin (IL)-1, tumour necrosis factor (TNF)- $\alpha$, and IL-6 [17, 20], may lead to clinical depression in vulnerable individuals [14]. Thus, we argue that systemic chronic low-grade inflammation, possibly 


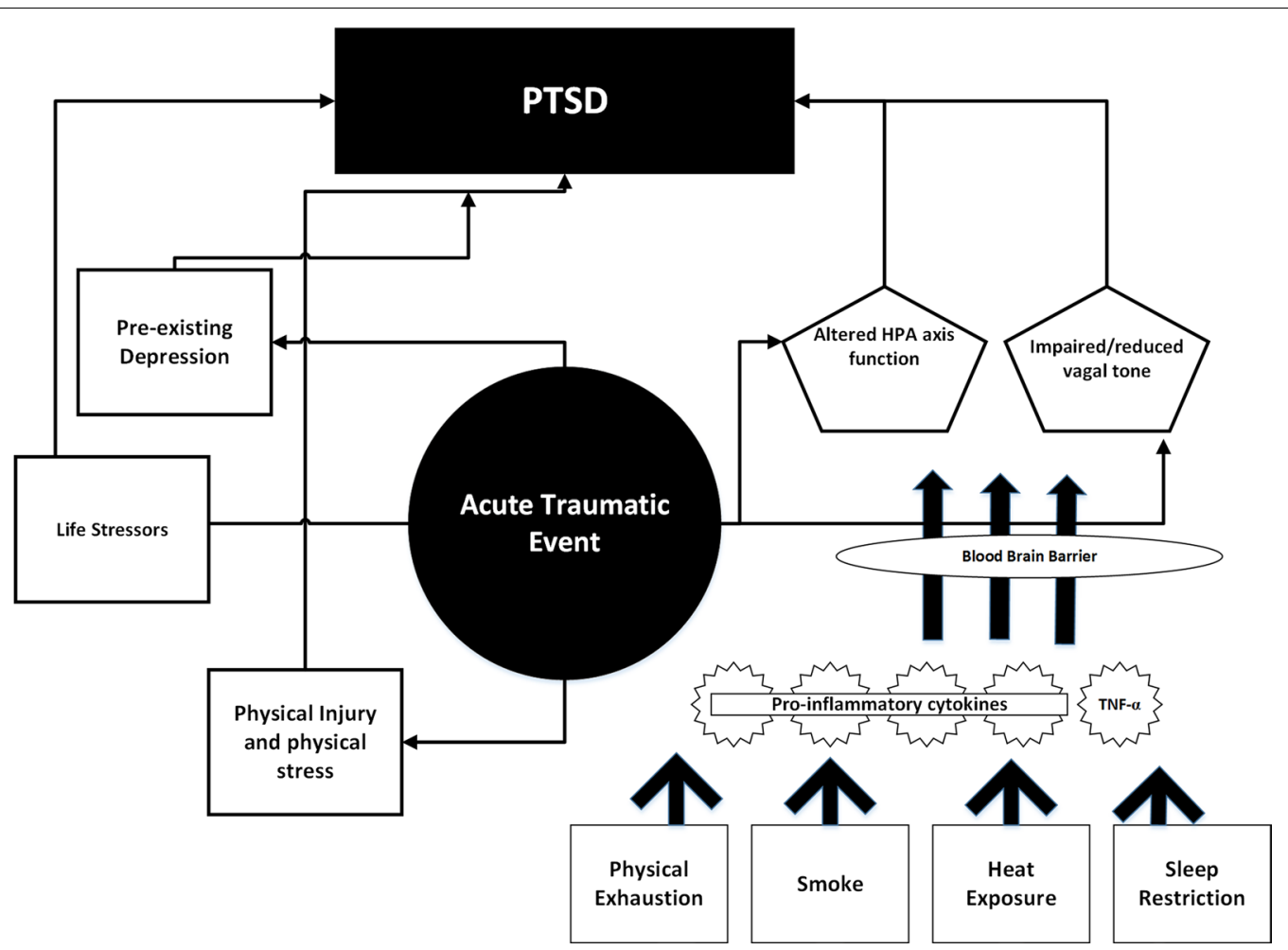

Fig. 1 Working model where pre-priming environmental and occupational work factors may predispose individuals to PTSD following exposure to acute traumatic events. By providing a pre-priming effect, it is likely that individual resilience may be compromised when faced with traumatic events at work

occurring as a result of numerous occupational stressors, may prime vulnerable individuals for an elevated risk of depressive disorders, especially when exposed to acute traumatic events.

\section{Cytokines}

Elevated pro-inflammatory cytokines, which, in first responders, may result from environmental exposures [21], have been linked to depression in the acute phase of PTSD [22-24] and during remission [25]. Coupled with increases in acute phase proteins, such as complement protein, C-reactive protein (CRP), and haptoglobin, elevated pro-inflammatory cytokines have been observed in major depression $[17,26]$. Specifically, depressed patients can exhibit substantially higher levels of IL- $1 \beta$ and IL-6 than non-depressed controls [27]. Higher levels of IL-6 (24.0 vs $14.6 \mathrm{pg} \mathrm{ml}^{-1}$ ) were observed in the cerebrospinal fluid of combat veterans suffering PTSD compared with non-depressed controls [28]. Such observations occur, since some cytokines can cross the BBB rapidly and access the CNS via several routes [18]. For example, TNF- $\alpha$ crosses the BBB within 30 min of exogenous injection [18]. Cytokines can enter the CNS via pathways that include direct access to brain structures, either using a saturable influx transport system (for IL-1 $\alpha$ and $\beta$, IL-6 and TNF- $\alpha$ ), or simple diffusion at the level of circumventricular organs, where the $\mathrm{BBB}$ is incomplete $[29,30]$. Cytokines may also reach the CNS indirectly via activation of afferent neurons [31] of the vagus nerve where they promote transcription and translation of other cytokines within the CNS [32]. A systemic increase in pro-inflammatory cytokines and their movement to the brain thus conveys information about metabolic, gastrointestinal, and cardiovascular challenges to brain regions that mediate stress-related behaviour [17], in particular, sickness depressive- and anxiety-like behaviours [33].

Specific receptors for IL- $1 \alpha$, IL-6, and TNF- $\alpha$ have a discrete distribution in the brain. For example, IL- $1 \alpha$ and IL- 6 receptors are abundant in the hypothalamus [31] and hippocampal areas [34]. Blocking IL-1 $\alpha$ receptors in the brain can prevent some of the sickness responses to peripheral administration of cytokines [35]. Further evidence of the role of these cytokines comes in the form of a recent meta-analysis showing depressed patients exhibit two-fold higher levels of IL-1 $\beta$ and IL- 6 than non-depressed controls [36]. IL- $1 \beta$ and IL- 6 can activate several discrete hypothalamic nuclei, which may account for many of the 
sickness-related behavioural changes, including hunger, thirst, sleep, reduced libido, and changes to resting body core temperatures [31]. Similarly, administration of certain cytokines, including IL- $1 \beta$ and IL-6, directly into the brain produces many or all of the sickness responses [35, 37]. Elevated cytokines may also interfere with cognitive processes, such as loss of attention and certain types of memory, an inability to concentrate at work, and reduced learning retention [31]. Any alterations of attention, memory, and/or learning may then, subsequently, decrease the ability of affected individuals to process their experience and reduces their long-term resilience [38].

One of the cytokine/CNS communication pathways for inflammation includes a dysregulated "fight-or-flight" response involving the autonomic nervous system and the hypothalamic-pituitary-adrenal (HPA) axis [39]. Activation of the HPA axis and sympathetic nuclei results in binding of cytokines in the hypothalamus, synthesis, and release of glucocorticoids [40] and increased levels of circulating catecholamines and cortisol [34, 41]. Compared with the general population, studies evaluating epinephrine and norepinephrine in PTSD have found increased resting levels [27, 42], while others have reported an exaggerated response after trauma-related stimulation [43]. However, the association of cortisol levels with traumatic exposures and PTSD is still not well understood. The hippocampus plays a role in modulating activity of the HPA axis [40] via a negative feedback system that involves glucocorticoids binding to receptors [44] in the hippocampus $[45,46]$. In the cases where HPA axis activation is sustained, possibly due to repeated stress, ongoing elevated glucocorticoid levels have been associated with mood impairments, including depression and PTSD [40, 47]. Clinical studies in traumatized individuals with PTSD have demonstrated a reduction in volume of the hippocampus with associated memory and learning deficits, indicating the neurotoxicity of cortisol [41]. However, while it may be assumed that individuals who develop PTSD following exposure to trauma might have sustained levels of cortisol [48], research has reported that a lower cortisol response to trauma is a predictor of subsequent PTSD symptoms in police officers and firefighters [49]. Impaired hippocampus function, related to repeat occupational stressors and chronically elevated cortisol levels, may be responsible for this inadequate cortisol response to trauma [48]. Consequently, in individuals with PTSD, or those susceptible to PTSD, an inadequate cortisol response following trauma may delay recovery by disrupting biological homeostasis acutely and possibly interfere with the interpretation of stressful information resulting in chronic disruptions in memory integration.
In addition to the measurement of catecholamines in PTSD, activity of the autonomic nervous system can be determined using heart rate variability (HRV) assessments [50, 51]. High HRV is associated with increased vagal/parasympathetic nervous system activity, whilst low HRV is linked with a withdrawal of vagal activity and a shift towards sympathetic nervous system dominance [51]. In addition to understanding the parasympathetic/sympathetic balance, HRV indices also provide information about an individual's ability to regulate inflammation. The vagus nerve plays an important role in regulating inflammation [52]. Specifically, it has been shown that cell production of inflammatory cytokines can be blocked via vagal nerve activity and that low HRV, indicative of vagal withdrawal, may reflect a reduced ability to regulate immune responses [52]. Recently, lower pre-deployment HRV (indicative of vagal withdrawal) reported in active-duty US marines [53] was associated with an increased prevalence of post-deployment PTSD [54]. Further research is required to characterise the acute and chronic relationships between HRV, inflammation, depression, and/or PTSD. Screening of first responders at varying stages in their career or during military pre-deployment activities might provide stronger evidence of this link.

\section{Occupational exposures}

Many military personnel and first responders work in hostile environments often characterised by high levels of heat $[55,56]$ and smoke [57], with altered sleep patterns [58] and risk of sustaining a physical injury [59]. Furthermore, work tasks, including wildfire suppression, complex technical rescues, and patrolling on foot (soldiers), can involve prolonged, strenuous bouts of physical activity. When this work is repeated over multiple days, as often occurs during responses to natural disasters and extended military deployments, individuals are also likely to experience reduced recovery and rest [58]. Collectively, these challenges could result in fatigue and exhaustion, contributing to a state of chronic low-grade systemic inflammation and/or altered immune status. We propose a model where chronic low-grade systemic inflammatory changes arising from prolonged occupational exposures in vulnerable first responders and military personnel may predispose this cohort to PTSD when exposed to subsequent traumatic events.

\section{Heat}

A growing body of evidence points to links between elevated core temperature $\left(T_{\mathrm{c}}\right)$ and increased immune system activity. Elevated levels of circulating leukocytes and platelets, and increased inflammatory activity, have been observed in firefighters following simulated work 
tasks in the heat [21, 60]. Strenuous physical activity undertaken in hot environments can also increase circulating levels of lipopolysaccharide (LPS) [61]. At rest and when the body is in a thermo-neutral state, the gastrointestinal mucosa protects the systemic environment from ingress of LPS, an endotoxin [62-65]. At low levels, the liver protects the body by eliminating LPS from circulation [66]. However, when $\mathrm{T}_{\mathrm{c}}$ increases substantially following work in the heat, intestinal permeability can increase, leading to accelerated migration of LPS into the circulatory system $[61,67,68]$. When LPS concentration rises rapidly in the blood, a range of pro-inflammatory responses, including IL- 1 , TNF- $\alpha$, and IL- 6 , are triggered [69-71]. Rising levels of LPS in the blood may then invoke a pathological systemic inflammatory response particularly in the presence of pre-existing suppressed immune surveillance for LPS, as has been shown in military personnel $[72,73]$.

Firefighters, tactical police, explosive ordinance disposal (EOD) operators, and soldiers wear personal protective clothing (PPC) and accoutrements. This protective clothing restricts movement [74] and can add substantial mass [75] to the ambulating individual. Furthermore, the need to provide first responders with protection from steam, chemicals, and biological attacks requires significant levels of encapsulation [76] along with protective equipment worn by soldiers and, increasingly, specialist, and general duties police officers. Wearing PPC (particularly "bunker gear", hazardous material (HAZMAT) protection, "bomb suits", and body armour) can create an uncompensable environment for operators resulting in an elevated $T_{\mathrm{c}}$. In work settings, PPC, thus, contributes to increases in $T_{\mathrm{c}}$ two ways: (i) via increasing metabolic heat production related to weight and binding [74], and (ii) limited body heat dissipation through reduced evaporative capacity [77].

While recommendations regarding post-incident rehabilitation and cooling are evolving [78, 79], it is unclear how many first response agencies or military organisations employ evidence-based practices following work in the heat [80]. As a result, workers may be redeployed following work tasks with elevated $T_{\mathrm{c}}$, possibly above recommended limits. Sustained elevations in $T_{\mathrm{c}}$ during these long duration exposures likely lead to increased immune and inflammatory activity, with post-heat inflammation observed for up to $24 \mathrm{~h}$ following simulated firefighting tasks in hot environments [21, 81, 82]. Given the recognised links between inflammation and depression, regular ongoing exposure to heat in the workplace, or sustained $T_{\mathrm{c}}$ elevations, may further contribute to the high rate of depression and PTSD in these populations if untreated.

\section{Smoke and toxic gases}

In addition to working in the heat, firefighters, in particular, face smoke, and toxic gases during fire suppression activities. Exposure to fine particulates, such as those in fire smoke and diesel exhausts from plant and machinery, promotes inflammation in the lungs $[57,83]$. Smokerelated inflammation in the lungs has subsequently been associated with acute increases in circulating IL-6 and TNF- $\alpha$ [57]. Respiratory symptoms at work were more prevalent in male Swiss firefighters compared with a control group from the general population. In this study, atopic diseases (including asthma and allergic rhinitis) were present in $51 \%$ of firefighters compared with $32 \%$ in a control group [84]. Recurrent depression and atopic diseases appear to be associated with atopy-related proinflammatory cytokines that play a role in the underlying mechanism [84].

While urban firefighters are generally protected from smoke and particulates by wearing self-contained breathing apparatus (SCBA), wildland firefighters generally operate without such protective equipment for extended durations, resulting in increased exposure to particulate matter, respiratory irritants, and systemic toxins, including asphyxiants [83, 85]. Furthermore, despite the protection offered to firefighters by wearing an SCBA, its effectiveness may be reduced during overhaul activities, when firefighters may doff their equipment and are subsequently exposed to off-gassing from burnt materials [86]. Improper supervision or poorly designed work practices may also see firefighters not fully protected by their SCBA, which must be considered by incident controllers when conducting fire suppression activities. The risk of contamination may be further increased when firefighters fail to engage in proper decontamination procedures at fire scenes, including entering rehabilitation sectors or travelling back to their station in contaminated PPC and SCBA.

\section{Sleep restriction}

Emergency first responder agencies provide a 24/7 response, requiring personnel to work and/or be oncall around the clock. Shiftwork and on-call work both cause well-described disruptions to sleep and the circadian rhythm [87-90]. The circadian rhythm in the brain drives sleep during the night hours and activity during the day hours. Shiftwork, and in particular night work, affects the circadian rhythm in two ways: (i) fighting to remain awake and alert at night is associated with reduced alertness and impaired performance, while (ii) fighting to fall and stay asleep during the day is associated with shorter and less restorative sleep. Thus, the shift worker deals with both compromised sleep and 
circadian misalignment [70-73]. The endocrine system also responds to sleep disturbance in the form of elevated cortisol [91] and downstream effects reducing HRV [92].

The effect of sleep deprivation on systemic inflammation and inflammatory markers is unclear. Some studies have demonstrated little effect of sleep deprivation on circulating leukocyte counts $[93,94]$ with effects similar to that of intense exercise (14), making an individual more susceptible to viral infections, such as the common cold and influenza $(15,16)$. In contrast, one night of sleep deprivation increased circulating leukocyte counts in another study [95]. Furthermore, higher pro- and antiinflammatory responses have been reported in healthy participants in laboratory studies involving sleep restriction or total sleep deprivation [78, 84, 85]. Using a more ecologically valid, field-simulated protocol, Wolkow and colleagues examined the sleep restriction which occurs on multi-day wildfire deployments and during 24/7 emergency responses [96]. A two-fold increase in resting levels of circulating pro-inflammatory IL-6 and a $14 \%$ increase in cortisol were observed in wildland firefighters following successive days of physical work $[58,96]$. These outcomes were mirrored in young male footballers who, after completing high-intensity work tasks following partial sleep deprivation, also demonstrated significant increases in IL-6 ( 25\%), TNF- $\alpha$ ( $69 \%)$, and growth hormone ( $25 \%)$ compared with undertaking training in a rested state $[97,98]$.

Sleep disruption is associated with depressive disorders $[99,100]$, but the causal relationship is not well defined. It is reasonable to assume that challenges associated with mental health issues may precipitate sleep disruption. A longitudinal study in military personnel points to sleep disturbance as a precursor to PTSD symptoms and depression [101] and inflammation associated with sleep disruption may play a role. Healthy men exposed to one night of sleep deprivation secreted higher daytime levels and lower night time levels of IL-6 than following a normal night's sleep. Furthermore, data from the control day indicated that better sleep quality was associated with lower daytime levels of IL-6 [102]. Inflammatory responses are linked to sleep disruption as well as depression, fatigue, sensitivity to pain, and cognitive impairments [103], and may precipitate adverse mood and mental health outcomes $[96,97,104,105]$.

\section{Physical exhaustion/overtraining}

When first responders and military personnel undertake strenuous physical work over multiple days, recovery may be limited, resulting in a condition similar to the symptoms of overtraining [106]. In athletic populations, overtraining manifests in reduced physical and cognitive performance [107] along with mood changes, excessive fatigue, and frequent illness [108]. High frequency of infection or illness symptoms in overtraining affected athletes is related to altered immunity, including increased inflammation and suppressed mucosal or cell-mediated immunity [109]. The altered immunity in overtraining athletes, or in athletes/workers following strenuous prolonged bouts of exercise, may be related to tissue damage up-regulating pro-inflammatory cytokines. These cytokines increase the risk of infection and/or non-infectious upper-respiratory symptoms [109, 110]. Elevated immune suppression and inflammatory reactions are usually self-limiting, particularly in healthy and well-rested athletic populations. However, when proper recovery is not achieved, as may occur during multi-day deployments, chronic inflammation and immune suppression may occur $[109,111]$. The overtraining-driven pro-inflammatory cytokine activation initiates changes in the hypothalamus, mood state, as well as the temperature set point [109], likely exacerbating the negative effects of working in the heat. Thus, efforts to reduce the likelihood of overtraining, or an imbalance between physical exhaustion, fatigue, and recovery, in operational populations may increase the rate of PTSD.

\section{Physical injury}

Soldiers, in particular, face an increased likelihood of physical injury, while on deployment, and are increasingly exposed to the effects of high explosives, which are responsible for $\sim 60 \%$ of modern US combat-related casualties [112]. Ninety percent of combat veterans with more than five episodes report ailments, including neurological deficits and cognitive impairment [112]. Since the earliest days of high-explosive use in combat, soldiers have presented with PTSD symptoms, many previously referred to as "shell shock". However, until recently, the link between blast-related mild traumatic brain injury (TBI), characterised by altered or lost consciousness for up to $30 \mathrm{~min}$, and PTSD has been largely overlooked. This is despite $44 \%$ of US soldiers in Iraq presenting with PTSD reporting lost consciousness during deployment [113]. Furthermore, personnel exposed to blast-related mild TBI, regularly report persistent symptoms, including impaired concentration, memory problems, depression, and anxiety indicative of structural damage in the brain, including the hippocampus, amygdala, and cortex regions [112, 113]. It is possible, therefore, that an individual's ability to regulate fear during stressful or traumatic events can be impaired, resulting in insufficient cognitive resources and a greater incidence of PTSD [114]. While not exactly the same, these symptoms are similar to chronic traumatic encephalopathy (CTE), a condition seen in contact sports [112]. 
In addition to acute and repeated blast-related TBI, a study of Israeli soldiers reported that those who were injured in combat suffered an eight-fold increase in the incidence of PTSD compared with their healthy counterparts [59]. This outcome is consistent with studies of returned soldiers from the Vietnam conflict who presented a two- to three-fold increase in PTSD compared with uninjured personnel $[115,116]$, particularly should they be exposed to a penetrating brain injury and subsequent traumatic event [113].

In the context of PTSD, changes in the HPA axis arising from physical injury, such as TBI or an impact wound, are likely to play a role in increased incidence of PTSD and depression in returning servicemen and women [17]. Specifically, endocrine disturbances are common after TBI, including HPA axis failure and adrenal insufficiency [117]. Inadequate control of inflammation by the HPA axis, evidenced by a more positive association between cortisol and CRP during stress, can give rise to health problems [118]. Recently, Laurent et al. [119] argued that negative health consequences of chronically high activation or inadequate post-stress recovery in the HPA axis and inflammatory systems are more pronounced when they occur together. Intuitively, therefore, physical injuryinduced alterations in the HPA axis and dysregulation of inflammation may present as contributors to depression and PTSD. However, despite post-mortem examinations of TBI-affected soldiers, to date, clinical biomarkers are yet to be established to enable "real-time" monitoring of vulnerable personnel [112].

\section{Testing the hypothesis}

To test the hypothesis presented in the present paper, a case-control approach is suggested that compares individuals with PTSD or depressive disorders with healthy colleagues in a retrospective framework. This framework should aim to characterise the relationships between altered immune and inflammatory activity, HPA activity, and health outcomes. The experimental approach needs to consider the involvement of heat, smoke, sleep restriction, physical exertion, inflammatory activity, and HPA axis modification. Initially, the involvement of these factors could be identified in part by questionnaire, wearable monitoring devices, and formal experimentation. The following list of measures should be useful in evaluating the hypothesis.

\section{Heat}

- Baseline immune, inflammatory, HPA, and HRV markers to assess whether some individuals are more at risk of depression.

- Body composition and fitness assessment.

- The impact of multiple exposures over multiple days.
Limited research exists with first responders and military personnel when they work in the heat; rather data are generally collected in controlled laboratory experiments or simulations in the field. To test the hypothesis that working in the heat elicits immune and inflammatory changes, combining data obtained in the field, during actual operations, with workers compensation data (specifically PTSD and depressive disorder claims) are needed to provide evidence of this possible link. Given the proven validity of relatively easy to deploy monitoring tools, such as ingestible core temperature sensors, heart rate monitors, and other wearables, these can be used during long duration, pre-planned responses. Furthermore, examination of cortisol responses over multiple days may provide further understanding of the role of heat as a stressor contributing to depressive disorders [120].

While recommendations regarding post-incident rehabilitation and cooling continue to evolve $[66,67]$, it is unclear how many first response agencies or military organisations engage in evidence-based practices for heat-affected workers [68]. For instance, the National Fire Protection Association (NFPA) recommends that firefighters attend recovery areas at emergencies following two work sessions in hot environments [78], an established protocol in other jurisdictions [55]. However, many fire services rely on more traditional passive cooling protocols, namely fluid replacement and shade, as a surrogate for proper active methods resulting in poor cooling rates [80]. Further research into the relationships between post-incident cooling and possible reductions in immune activity should be explored to evaluate whether current cooling practices can be improved.

\section{Smoke}

- Measurement or reporting of off-gassing PPE.

- Comparison of immune and inflammatory responses in wildland compared with urban firefighters wearing SCBA.

- Baseline and ongoing monitoring of firefighters during emergency responses and deployments.

Atmospheric monitoring of operating environments can be easily achieved using the modern technology, including photo-ionisation-detection (PID) devices, and other detectors already used in many urban fire services. This approach can give some clarity to the degree of particulate exposure in the field. Furthermore, laboratory examination of soiled PPE can give further evidence of levels of exposure and also exposure types during fire suppression activities. This data can then be compared with changes to baseline immune and inflammatory responses of firefighters following exposure in the field, 
particularly in wildland firefighters who generally operate without the protection offered by an SCBA. Furthermore, many urban fire services now test for exposure to carbon monoxide following fire suppression-this will add further information regarding possible exposure limits of firefighters.

\section{Sleep restriction}

- Self-reported assessments of sleep quality and quantity.

- Remote monitoring of sleep using wearable devices.

- Detailed reporting of work, exercise and other activities, and rest times.

We propose that sleep plays a role in both susceptibility to and development of PTSD, as well as being a symptom of PTSD and depressive disorders. Thus, it will be important to collect information on subjective sleep quality and quantity under various operational and rest scenarios. In observational studies, objective sleep information can be collected using wearables and other validated devices to determine the amount of sleep obtained in given opportunities and to identify relationships between sleep and other stressors on negative health outcomes. Organisations and individuals should also be aware of the impact of sleep disorders on sleep quality and quantity, and the acute and long-term implications for performance, health, and well-being [121]. Screening for sleep disorders should be considered part of a fatigue risk management system.

\section{Physical exertion/overtraining/injury}

- Self-reported activity, fatigue, and injury records (e.g., online or smartphone capture).

- Biomarker relationships with resilience (e.g., wearable devices to quantify movements, HRV monitoring, other physiological indices).

- Pre-deployment state and relationship to outcomes (e.g., fitness status and health outcomes post-deployment).

In first responder and military populations, examining the links between acute stressors and exercise, or, perhaps, fitness, as a mediating factor is worthy of investigation. In elite athletic cohorts, HRV monitoring is used to assess training status and the presence of non-functional overreaching [122]. Examining HRV to diagnose fatigue, possibly using short 5-min recordings on awakening in the morning, using a domain index RMSSD (square root of the mean of the sum of the squares of differences between adjacent normal $\mathrm{R}-\mathrm{R}$ intervals) is considered reliable and practical in athletic populations [123]. This approach could be used during deployments of first responders and soldiers to monitor changes and possibly allow for early interventions. Lower HRV (reduced vagal drive) may function as a predictor of vulnerability to inflammatory-related depression [52] to provide a warning sign in first responders. Previously, changes in HPA function have been observed in combat veterans in the form of low cortisol levels $[28,46]$ and a disrupted autonomic nervous system (ANS) [47]. Lower HRV has also been associated with PTSD in active-duty US marines [54]. Screening of first responders and military personnel together with chronic monitoring of HRV will provide stronger evidence of this link. Furthermore, examining the combination of appropriate recruitment standards, wellness (fitness) programs, and pre-deployment screenings is likely to play an important role in mitigating the high rates of PTSD and depressive symptoms.

\section{Implications of the hypothesis}

While inflammation is not likely to account for all episodes of depression or PTSD in first responders, an underlying inflammatory state is likely in many circumstances. Identifying workplace risks, particularly those related to physical and environmental stress, in addition to acute traumatic stressors, would be a prudent approach to mitigate the high rates of depression and PTSD in first responders. This approach may involve strategies, such as reducing exposure to environmental and occupational factors, screening or monitoring programs, and education of personnel, supervisors, and management. Building individual resilience is also likely to be a meaningful proactive strategy. Practical interventions in need of further research which may reduce the risk of depressive disorders are summarised in Table 1.

\section{Improving fitness}

Properly conditioning workers should enable them to safely complete work tasks in a range of occupational settings $[124,125]$. This outcome is likely related to a higher capacity to sustain work, and, therefore, reduced stress given any particular workload. Further to fitness, body composition plays a role in the higher risk of injuries in overweight and obese firefighters [126]. This is an important issue in modern fire services with the rates of overweight and obese firefighters continuing to increase [127, 128]. Although the military services regularly test for the fitness of their personnel, this is, generally, not the case in emergency response agencies [129].

Fitness and improved body composition are associated with a better capacity to tolerate heat [130]. A study of US Marine Corp recruits showed those in poorer physical condition (reflected in slower run times and lower predicted $\mathrm{VO}_{2 \text { max }}$ ) were up to six times more likely to suffer an exertional heat illness than their fitter colleagues 
Table 1 Practical interventions that may mitigate the effects of acute traumatic events prior to developing PTSD

\begin{tabular}{|c|c|c|}
\hline Strategy & Intervention & Possible outcome? \\
\hline \multirow[t]{4}{*}{ Increasing resilience } & Increase fitness & Reduced relative work intensity for individuals \\
\hline & $\begin{array}{l}\text { Managing fatigue-appropriate } \\
\text { work/rest cycles }\end{array}$ & Reduced fatigue and risk of overtraining \\
\hline & Psychological screening & $\begin{array}{l}\text { At risk, individuals may be removed prior to exposure or proactive, } \\
\text { targeted interventions are put in place }\end{array}$ \\
\hline & Injury management/rehabilitation & $\begin{array}{l}\text { Proper injury management, particularly in the form of early interven- } \\
\text { tion will reduce the duration of injury and possibly related immune } \\
\text { changes }\end{array}$ \\
\hline \multirow[t]{4}{*}{ Working in the heat/smoke } & Appropriate PPC selection for the task & Reduced thermal strain of workers \\
\hline & Pre-cooling of workers & $\begin{array}{l}\text { Reduced thermal strain during work events possibly due to lower peak } \\
T_{c}\end{array}$ \\
\hline & Post-incident cooling & $\begin{array}{l}\text { Reduce inflammation to resting state as soon as possible following } \\
\text { work. Reduce } T_{c} \text { rapidly to baseline levels }\end{array}$ \\
\hline & Appropriate work/rest cycles & Minimising $T_{c}$ rise and subsequent inflammatory activity \\
\hline \multirow[t]{4}{*}{ Sleep deprivation } & Cognitive behaviour therapy & $\begin{array}{l}\text { Individuals demonstrating sleeping disorders may improve the quality } \\
\text { and duration of sleep }\end{array}$ \\
\hline & Sleep hygiene & $\begin{array}{l}\text { Individuals will have better strategies for managing sleep in the field } \\
\text { and during deployments }\end{array}$ \\
\hline & Screening for sleep disorders & Individuals can be targeted for interventions \\
\hline & Rostering for rest periods & Reduced fatigue of possibly at-risk individuals \\
\hline
\end{tabular}

[131]. Thus, improving the fitness and body composition of workers should improve their resilience to workrelated physical stress.

\section{Post incident rehabilitation-include cooling strategies}

To allow for proper post-incident recovery, and reduce the likelihood of operators developing non-functional overreaching, incident controllers must consider rehabilitation when planning for long-duration responses. Reduced sleep is likely to be a contributing factor during multi-day responses. Protecting sleep during incidents can be provided in two ways-adequate time for sleep away from the incident ground between work periods and a suitable sleeping environment which reduces the impact of heat, noise, and light [132]. Hence, addressing sleep quality will likely improve mental health in the field. In relation to post-incident recovery, extended or ad lib night sleep opportunities can promote recovery in a range of outcomes, including performance [133, 134], subjective fatigue, and sleepiness [135]. This process involves nighttime sleep opportunities unrestricted by work requirements following an incident. Rostering guidelines should include a number of days 'off' before returning to the incident, or responding to a subsequent incident.

\section{Conclusion}

Elevated rates of depression and PTSD in vulnerable occupational populations, in addition to acute traumatic events, could be linked with exposures in their working environments. Exposure to heat, smoke, injury, repeated physical work, and sleep deprivation appears to elicit inflammatory changes that may be priming first responders and military personnel to react adversely to acute traumatic events increasing the risk of PTSD. These environmental exposures should be considered as part of a risk management approach to mitigating PTSD in these populations. A case-control experimental approach is needed to compare individuals with PTSD or depressive disorders with healthy colleagues for characterising relationships between altered immune and inflammatory activity and health outcomes. Appropriate conditioning and identifying at-risk personnel prior to deployment to physical environments characterised by heat, smoke, physical trauma, and sleep deprivation are priorities for first responder and military organisations.

\section{Abbreviations}

ANS: autonomic nervous system; BBB: blood brain barrier; CNS: central nervous system; CRP: C-reactive protein; CTE: chronic traumatic ecephalopathy; Gl: gastrointestinal; EOD: explosive ordinance device; HAZMAT: hazardous materials; HPA: hypothalamic-pituitary-adrenal; HRV: heart rate variability; IL: interleukin; LPS: lipopolysaccharide; NFPA: National Fire Protection Association (USA); PID: photo-ionisation detector; PPC: personal protective clothing; PTSD: post-traumatic stress disorder; RMSSD: the square root of the mean of the sum of the squares of differences between adjacent normal R-R intervals; SCBA: self-contained breathing apparatus; $T B I$ : traumatic brain injury; $T_{c}$ : core temperature; TNF: tumour necrosis factor.

\section{Authors' contributions}

AW conceived and developed this hypothesis paper and took a lead role in the development and writing. AM, SF, DP, and BR all made a significant and equal contribution to this paper by providing their knowledge and in drafting and ongoing editing. All authors read and approved the final manuscript. 


\begin{abstract}
Author details
${ }^{1}$ University of Canberra Research Institute for Sport and Exercise, University of Canberra, Canberra, Australia. ${ }^{2}$ Australian Capital Territory Fire \& Rescue, Canberra, Australia. ${ }^{3}$ Discipline of Sport and Exercise Science, Faculty of Health, University of Canberra, Canberra, Australia. ${ }^{4}$ Appleton Institute, School of Human Health and Social Sciences, Central Queensland University, Adelaide, Australia. ${ }^{5}$ Department of Physiology, Australian Institute of Sport, Canberra, Australia
\end{abstract}

\section{Acknowledgements}

Not applicable.

\section{Competing interests}

The authors declare that they have no competing interests.

Received: 11 April 2016 Accepted: 28 June 2016

Published online: 15 July 2016

\section{References}

1. Kolkow TT, Spira JL, Morse JS, Greiger TA. Post-traumatic stress disorder and depression in health care providers returning from deployment to Iraq and Afghanistan. Mil Med. 2007;172:451-5.

2. Fullerton CS, Ursano RJ, Wang L. Acute stress disorder, posttraumatic stress disorder, and depression in disaster or rescue workers. Am J Psychiatry. 2004;161:1370-6.

3. Hoffman JR, Ishay O, Zeev K, Zohar J, Cohen H. Exercise enhances the behavioural responses to acute stress in an animal model of PTSD. Med Sci Sports Exerc. 2015;47:2043-52.

4. Benedek D, Fullerton CS, Ursano R. First responders: mental health consequences of natural and human-made disasters for public health and public safety workers. Annu Rev Public Health. 2007;28:55-68

5. North CS, Tivis L, McMillen JC, Pfefferbaum B, Spitznagel EL, Cox J, Nixon $\mathrm{S}$, Bunch KP, Smith EM. Psychiatric disorders in rescue workers after the Oklahoma City bombing. Am J Psychiatry. 2002;159:857-9.

6. Orman DT, Robichaux RJ, Crandall EO, Patterson VJ, Hoge CW, Engel CC, Ritchie E, Milliken CS. Operation Solace: overview of the mental health intervention following the September 11, 2001 Pentagon attack. Mil Med. 2002;167:44-7.

7. Marmar C, McCaslin S, Metzler T, Best S, Weiss D, Fagan J, Liberman A, Pole N, Otte C, Yehuda R, et al. Predictors of post-traumatic stress in Police and other First Responders. Ann NY Acad Sci. 2006;1071:1-18.

8. McFarlane AC, Papay P. Multiple diagnosis in posttraumatic stress disorder in the victims of a natural disaster. J Nerv Ment Dis. 1992;180:498-504

9. Morren M, Yzermans CJ, van Nispen RMA, Wevers JM. The health of volunteer firefighters three years after a technological disaster. J Occup Health. 2005:47:523-32.

10. Breslau N, Davis GC, Petersen EL, Schultz LR. A second look at comorbidity in victims of trauma: the posttraumatic stress disorder-major depression connection. Biol Psychiatry. 2000;48:902-9.

11. Heinrichs M, Wagner D, Schoch W, Soravia LM, Hellhammer DH, Elhert $U$. Predicting posttraumatic stress symptoms from pretraumatic risk factors: a 2-year prospective follow up study in firefighters. Am J Psychiatry. 2005:162:2276-86.

12. Hoge CW, Castro CA, Messer SC, McGurk D, Cotting DI, Koffman RL. Combat duty in Iraq and Afghanistan, mental health problems, and barriers to care. N Engl J Med. 2004;351:13-22.

13. Hart BL. Biological basis of the behaviour of sick animals. Neurosci Behav Rev. 1988;12:123-37.

14. Dantzer R, Vichaya E, Walker A. Inflammation-induced depression: evidence and mechanisms. J Neuroimmunol. 2014;275:146.

15. Kluger MJ, Vaughan LK. Fever and survival in rabbits infected with pasteurella multocida. J Physiol. 1978;28:243-51.

16. Kelley KW, Bluthe RM, Dantzer R, Zhou ES, Shen WH, Johnson RW, Broussard SR. Cytokine-induced sickness behaviour. Brain Behav Immun. 2003;17:S112-8.

17. Maes M, Berk M, Goehler L, Song C, Anderson G, Galecki P, Leonard B. Depression and sickness behavior are Janus-faced responses to shared inflammatory pathways. BMC Med. 2012;10:66
18. Yarlagadda A, Alfson E, Clayton AH. The blood brain barrier and the role of cytokines in neurophsychiatry. Psychiatry (Edgmont). 2009;6:18-22.

19. Dantzer R, O'Connor JC, Freund GG, Johnson RW, Kelley KW. From inflammation to sickness and depression: when the immune system subjugates the brain. Nature Reviews Neurosciences. 2008;9:46-56.

20. Krabbe KS, Reichenberg A, Yirmiya R, Smed A, Pedersen BK, Bruunsgaard H. Low-does endotoxemia and human neuropsychological functions. Brain Behav Immun. 2005;18:435-60.

21. Walker A, Keene T, Argus C, Driller M, Guy JH, Rattray B. Immune and inflammatory responses of Australian firefighters after repeated exposures to the heat. Ergonomics. 2015:58:2032-9.

22. Frommberger UH, Bauer J, Haselbauer OP, Fraulin A, Riemann D, Berger M. Interleukin-6 (IL-6) plasma levels in depression and schizophrenia: comparison between the acute state and after remission. Eur Arch Psychiatry Clin Neurosci. 1997;247:228-33.

23. Sluzewska A, Rybakowski JK, Bosmans E, Sobieska M, Berghamans $\mathrm{R}$, Maes M, Wiktorowicz K. Indicators of immune activation in major depression. Psychiatry Res. 1996;64:161-7.

24. Sluzewska A, Rybakowski JK, Laciak M, Mackiewicz A, Sobieska M, Wiktorowicz K. Interleukin-6 serum levels in depressed patients before and after treatment with fluoxetine. Ann NY Acad Sci. 1995;762:474-6.

25. Maes M. Evidence for an immune response in major depression: a review and hypothesis. Prog Neuropsychopharmacol Biol Psychiatry. 1995;19:11-38.

26. Berk M, Wadee AA, Kuschke RH, O'Neill-Kerr A. Acute phase proteins in major depression. J Psychosom Res. 1997;43:529-34.

27. Kosten TR, Mason JW, Giller EL, Ostroff RB, Harkness L. Sustained urinary norepinephrine and epinephrine elevation in post-traumatic stress disorder. Psychoneuroendocrinology. 1987;12:13-20.

28. Baker DG, Ekhator NN, Kasckow JW, Hill KK, Zoumakis E, Dashevsky BA, Chrousos GP, Geracioti TDJ. Plasma and cerebrospinal fluid interleukin-6 concentrations in posttraumatic stress disorder. Neurolmmunomodulation. 2001;9:209-17.

29. Kent S, Bluthe R, Dantzer R, Hardwick AJ, Kelley KW, Rothwell NJ, Vannice $J$. Different receptor mechanisms mediate the pyrogenic and behavioural effects of interleukin-1. Trends Pharmacol Sci. 1992:13:24-8.

30. Schobitz B, de Kloet ER, Holsboer F. Gene expression and function of interleukin-1, interleukin-6 and tumour necrosis factor in the brain. Prog Neurobiol. 1994:44:397-432

31. Maier SF, Watkins LR. Cytokines for psychologists: Implications of bidirectional immune-to-brain communication for understanding behaviour, mood and cognition. Psychol Rev. 1998;105:83.

32. Dantzer R. How do cytokines say hello to the brain? Neural vs humoral mediation. Eur Cytokine Netw. 1994;5:271-3.

33. Goehler L, Lyte M, Gaykema RP. Infection-induced viscerosensory signals from the gut enhance anxiety: implications for psychoneuroimmunology. Brain Behav Immun. 2007;21:721-6.

34. Goshen I, Kreisel T, Ben-Menachem-Zidon O, Licht T, Weidenfeld J, BenHur T, Yirmiya R. Brain interleukin-1 mediates chronic stress-induced depression in mice via adrenocortical activation and hippocampal neurogenesis suppression. Mol Psychiatry. 2008;13:717-28.

35. Rothwell NJ, Hopkins SJ. Cytokines and the nervous system II: actions and mechanisms of action. Trends Neurosci. 1995;18:130-6.

36. Passos IC, Vasconcelos-Moreno MP, Costa LG, Kunz M, Brietzke E, Quevedo J, Salum G, Magalhaes PV, Kapczinski F, Kauer-Sant'Anna M. Inflammatory markers in post-traumatic stress disorder: a systematic review, meta-analysis, and meta-regression. Lancet Psychiatry. 2015:2:1002-12.

37. Dinarello CA. Interleukin-1 and interleukin-1 antagonism. Blood. 1991;77:1627-52.

38. Guina J, Rossetter SR, DeRhodes BJ, Nahhas RW, Welton RS. Benzodiazepines for PTSD: a systematic review and meta-analysis. J Psychiatr Pract. 2015:21:281-303.

39. Gill JM, Saligan L, Woods S, Page G. PTSD is associated with an excess of inflammatory immune activities. Perspect Psychiatr Care. 2009;54:262-77.

40. Joca SR, Ferreira FR, Guimaraes FS. Modulation of stress consequences by hippocampal monoaminergic, glutamatergic and nitrergic neurotransmitter systems. Stress. 2007:10:227-49.

41. O'Brien JT, Lloyd A, McKeith I, Gholkar A, Ferrier N. A longitudinal study of hippocampal volume, cortisol levels, and cognition in older depressed subjects. Am J Psychiatry. 2004;161:2081-90. 
42. McFall ME, Veith RC, Murburg MM. Basal sympathoadrenal function in posttraumatic distress disorder. Biol Psychiatry. 1992;31:1050-6.

43. Costa GDM. New insights into cortisol levels in PTSD. Rev Bras Psiquiatr. 2016:38:176.

44. de Kloet ER. Hormones, brain and stress. Endocr Regul. 2003;37:51-68.

45. Herman JP, Ostrander MM, Mueller NK, Figueiredo H. Limbic system mechanisms of stress regulation: hypothalamo-pituitaryadrenocortical axis. Prog Neuropsychopharmacol Biol Psychiatry. 2005;29:1201-13.

46. Bremner JD, Narayan M. The effects of stress on memory and the hippocampus throughout the life cycle: implications for childhood development and aging. Dev Psychopathol. 1998;10:871-85.

47. Het S, Wolf OT. Mood changes in response to psychosocial stress in healthy young women: effects of pretreatment with cortisol. Behav Neurosci. 2007;121:11-20.

48. Zohar J, Yahalom H, Kozlovsky N, Cwikel-Hamzany S, Matar MA, Kaplan $Z$, Yehuda R, Cohen H. High dose hydrocortisone immediately after trauma may alter the trajectory of PTSD: interplay between clinical and animal studies. Eur Neuropsychopharmacol. 2011;21:196-809.

49. Witteveen AB, Huizink AC, Slottje P, Bramsen I, Smid T, Van Der Ploeg HM. Associations of cortisol with posttraumatic stress symptoms and negative life events: a study of police officers and firefighters. Psychoneuroendocrinology. 2010;35:1113-8.

50. Meyer P-W, Müller LE, Zastrow A, Schmidinger I, Bohus M, Herpertz SC, Bertsch $\mathrm{K}$. Heart rate variability in patients with post-traumatic stress disorder or borderline personality disorder: relationship to early life maltreatment. J Neural Transm. 2016. doi:10.1007/s00702-016-1584-8.

51. Botek M, McKune AJ, Krejci J, Stejskal P, Gaba A. Change in performance in response to training load adjustment based on autonomic activity. Int J Sports Med. 2014;35:482-8.

52. Huston JM, Tracey KJ. The pulse of inflammation: heart rate variability, the cholinergic anti-inflammatory pathway, and the implications for therapy. J Intern Med. 2011;269:45-53.

53. Papaioannou V, Pneumatikos I, Maglaveras N. Association of heart rate variability and inflammatory response in patients with cardiovascular diseases: current strengths and limitations. Front Physiol. 2013;4:174.

54. Minassian A, Maihofer AX, Baker DG, Nievergelt CM, Risbrough VB. Association of predeployment heart rate variability with risk of postdeployment posttraumatic stress disorder in active-duty marines. JAMA Psychiatry. 2015;72:979-86.

55. Walker A, Argus C, Driller M, Rattray B. Repeat work bouts increase thermal strain for Australian firefighters working in the heat. Int J Occup Environ Health. 2015;21:285-93.

56. Smith DL, Petruzzello SJ, Goldstein E, Ahmad U, Tangella K, Freund GG Horn GP. Effect of live-fire training drills on firefighters' platelet number and function. Prehosp Emerg Care. 2011;15:233-9.

57. Swiston JR, Davidson W, Attridge S, Li GT, Brauer M, van Eeden SF. Wood smoke exposure induces a pulmonary and systemic inflammatory response in firefighters. Eur Respir J. 2008;32:129-38.

58. Wolkow A, Aisbett B, Reynolds J, Ferguson SA, Main L. The impact of sleep restriction while performing simulated physical firefighting work on cortisol and heart rate responses. Int Arch Occup Environ Health. 2015;89(3):461-75.

59. Koren D, Norman D, Cohen A, Berman J, Klein EM. Increased PTSD risk with combat-related injury: a matched comparison study of injured and uninjured soldiers experiencing the same combat events. Am J Psychiatry. 2005:162:276-8.

60. Smith DL, Petruzzello SJ, Chludzinski MA, Reed JJ, Woods JA. Selected hormonal and immunological responses to strenuous live-fire firefighting drills. Ergonomics. 2005;48:55-65.

61. Pyne DB, Guy JH, Edwards AM. Managing heat and immune stress in athletes with evidence-based strategies. Int I Sports Physiol Perform. 2014;9:744-50.

62. Gisolfi CV. Is the Gl system built for exercise. Physiology. 2000;15:114-9.

63. Hall DM, Baumgardner KR, Oberley TD, Gisolfi CV. Mechanisms of circulatory and intestinal barrier disfunction during whole body hyperthermia. Am J Physiol Heart Circ Physiol. 1994;280:H509-21.

64. Leon $L R$, Helwig BG. Heat stroke: role of the systemic inflammatory response. J Appl Physiol. 2010;109:1980-8.

65. Leon LR, Bouchama A. Heat stroke. Compr Physiol. 2015;5:611-47.
66. Gathirim P, Wells MT, Brock-Utne JG, Wessels BC, Gaffin SL. Prevention of endotoxaemia by non-absorbable antibiotics in heat stress. J Clin Pathol. 1987:40:1364-8.

67. Moseley PL. Heat shock proteins and heat adaptation of the whole organism. J Appl Physiol. 1997;83:1413-7.

68. Selkirk GA, McLellan TM, Wright HE, Rhind SG. Mild endotoxemia, NF-KB translocation, and cytokine increase during exertional heat stress in trained and untrained individuals. Am J Physiol Regul Integr Comp Physiol. 2008;295:R611-23.

69. Bosenberg AT, Brock-Utne JG, Gaffin MTB, Blake GTW. Strenuous exercise causes systemic endotoxemia. J Appl Physiol. 1988;65:106-8.

70. Bouchama A, Parhar RS, el-Yazigi A, Sheth K, al-Sedairy S. Endotoxemia and release of tumor necrosis factor and interleukin 1 alpha in acute heatstroke. J Appl Physiol. 1991;70:2640-4.

71. Sakurada S, Hales JR. A role for gastrointestinal endotoxins in enhancement of heat tolerance by physical fitness. J Appl Physiol. 1998;84:207-14.

72. Lim CL, Mackinnon LT. The roles of exercise-induced immune system disturbances in the pathology of heat stroke. Sports Med. 2006;36:39-64.

73. Kramer TR, Moore RJ, Shippee RL, Friedl KE, Martinez-Lopez L, Chan MM, Askew EW. Effects of food restriction in military training on T-lymphocyte responses. Int I Sports Med. 1997;18:S84-90.

74. Dorman LE, Havenith G. The effects of protective clothing on energy consumption during different activities. Eur J Appl Physiol. 2009:105:463-70.

75. Smith DL, Fehling PC, Hultquist EM, Lefferts WK, Barr D, Storer TW, Cooper CB. Firefighter's personal protective equipment and the chronotropic index. Ergonomics. 2012;55:1243-51.

76. Nayak R, Houshyar S, Padhye R. Recent trends and future scope in the protection and comfort of fire-fighters' personal protective clothing. Fire Sci Rev. 2014;3:1-19.

77. Cheung SS, McLellan TM. Influence of hydration status and fluid replacement on heat tolerance while wearing NBC protective clothing. Eur J Appl Physiol. 1997;77:139-48.

78. NFPA: NFPA 1584, Standard on the rehabilitation process for members during emergency operations and training exercises. National fire protection association; 2008.

79. Brearley M, Walker A. Water immersion for post incident cooling of firefighters; a review of practical fire ground cooling modalities. Extrem Physiol Med. 2015;4:1-13.

80. Walker A, Driller M, Brearley M, Argus C, Rattray B. Cold water immersion and iced slush ingestion are effective at cooling firefighters following a simulated search and rescue task in a hot environment. Appl Physio Nutr Metab. 2014;39:1159-66.

81. Smith DL, Petruzzello SJ, Chludzinski MA, Reed JJ, Woods JA. Effect of strenuous live-fire firefighting drills on hematological, blood chemistry and psychological measures. J Therm Biol. 2001;26:375-9.

82. Horn GP, Gutzmer S, Fahs CA, Petruzzello SJ, Goldstein E, Fahey GC, Fernhall B, Smith DL. Physiological recovery from firefighting activities in rehabilitation and beyond. Prehosp Emerg Care. 2011;15:214-25.

83. Naeher LP, Brauer M, Lipsett M, Zelikoff JT, Simpson CD, Koenig JQ, Smith KR. Woodsmoke health effects: a review. Inhal Toxicol. 2007;19:67-106.

84. Miedinger D, Chhajed PN, Stolz D, Gysin C, Wanzenried A-B, Schindler C, Surber C, Bucher HC, Tamm M, Leuppi JD. Respiratory symptoms, atopy and bronchial hyperreactivity in professional firefighters. Eur Respir J. 2007;30:538-44.

85. Stefanidou M, Athanaselis S, Spiliopoulou C. Health impacts of fire smoke inhalation. Inhal Toxicol. 2008:20:761-6.

86. Burgess JL, Nanson CJ, Hysong TA, Gerkin R, Witten ML, Clark Lantz R. Rapid decline in sputum IL-10 concentration following occupational smoke exposure. Inhal Toxicol. 2002;14:133-40.

87. Akerstedt T. Shift work and disturbed sleep/wakefullness. Sleep Med Rev. 1998;2:117-28.

88. Rajaratnam SMW, Arendt J. Health in a 24-hr society. The Lancet. 2001;358:999-1005.

89. Folkard S, Lombardi DA, Tucker PT. Shiftwork: safety, sleepiness and sleep. Ind Health. 2005;43:20-3.

90. Costa G. The problem: shiftwork. Chronobiol Int. 1997;14:89-98. 
91. Leproult R, Copinschi G, Buxton O, Van Cauter E. Sleep loss results in an elevation of cortisol levels the next evening. Sleep. 1997;20(10):865-70.

92. Takase B, Akima T, Satomura K, Ohsuzu F, Mastui T, Ishihara M, Kurita A. Effects of chronic sleep deprivation on autonomic activity by examining heart rate variability, plasma catecholamine, and intracellular magnesium levels. Biomed Pharmacother. 2004;58:S35-9.

93. Heiser P, Dickhaus B, Schreiber W, Clement HW, Hasse C, Hennig J, Remschmidt H, Krieg JC, Wesemann W, Opper C. White blood cells and cortisol after sleep deprivation and recovery sleep in humans. Eur Arch Psychiatry Clin Neurosci. 2000;250:16-23.

94. Costa Ricardo JS, Cartner L, Oliver SJ, Laing SJ, Walters R, Bilzon JL, Walsh NP. No effect of a 30-h period of sleep deprivation on leukocyte trafficking, neutrophil degranulation and saliva IgA responses to exercise. Eur J Appl Physiol. 2009;105:499-504.

95. Born J, Lange T, Hansen K, Molle M, Fehm HL. Effects of sleep and circadian rhythm on human circulating immune cells. J Immunol. 1997;158:4454-64.

96. Wolkow A, Ferguson SA, Vincent GE, Larsen BL, Aisbett B, Main LC. The impact of sleep restriction and simulated firefighting work on acute inflammatory stress responses. PLoS One. 2015;10:e0138128.

97. Abedelmalek S, Souissi N, Chtourou H, Denguezli M, Aouichaoui C, Ajina M, Aloui A, Dogui M, Haddouk S, Tabka Z. Effects of partial sleep deprivation on proinflammatory cytokines, growth hormone, and steroid hormone concentrations during repeated brief sprint interval exercise. Chronobiol Int. 2013;30:502-9.

98. Abedelmalek S, Chtourou H, Aloui A, Aouichaoui C, Souissi N, Tabka Z. Effect of time of day and partial sleep deprivation on plasma concentrations of IL-6 during a short-term maximal performance. Eur J Appl Physiol. 2013;113:241-8.

99. Haak M, Mullington JM. Sustained sleep restriction reduces emotional and physical well-being. Pain. 2005;1 19:56-64.

100. Durmer JS, Dinges DF. Neurocognitive consequences of sleep deprivation. Semin Neurol. 2005:25:117-29.

101. Wright KM, Britt TW, Bliese PD, Adler AB, Picchioni D, Moore D. Insomnia as a predictor versus outcome of PTSD and depression among Iraq combat veterans. J Clin Psychol. 2011;67:1240-58.

102. Vgontzas AN, Papanicolaou DA, Bixler EO, Lotsikas A, Zachman K, Kales A, Prolo P, Wong M, Licinio J, Gold PW, et al. Circadian interleukin-6 secretion and quantity and depth of sleep. J Clin Endocrinol Metab. 1999:84:2603-7.

103. Krueger JM. The role of cytokines in sleep regulation. Curr Pharm Des. 2008;14:3408-16.

104. Bhatt V, Diolombi M, Haak M, Mullington J. Effect of repeated exposure to sleep restriction on interleukin 6 levels in humans. FASEB J. 2015;29(1 Suppl):615-7.

105. Vgontzas AN, Zoumakis E, Bixler EO, Lin HM, Follett H, Kales A, Chrousos GP. Adverse effects of modest sleep restriction on sleepiness, performance, and inflammatory cytokines. J Clin Endocronol Metab. 2004:89(5):2119-26

106. Meeusen R, Duclos M, Foster C, Fry A, Gleeson M, Niemen D, Raglin J, Rietjens G, Steinacker J, Urhausen A. Prevention, diagnosis, and treatment of the overtraining syndrome: joint consensus statement of the European College of Sport Science and the American College of Sports Medicine. Med Sci Sports Exerc. 2013;45:186-205.

107. Smith LL. Tissue trauma: the underlying cause of overtraining syndrome? J Strength Cond Res. 2004;18:185-93.

108. MacKinnon LT. Special featrure for the Olympics: effects of exercise on the immune system: overtraining effects on immunity and performance in athletes. Immunol Cell Biol. 2000;78:502-9.

109. Smith LL. Overtraining, excessive exercise, and altered immunity: is this a T helper-1 versus T helper-2 lymphocyte response? Sports Medicine. 2003:33:347-64

110. Smith LL. Cytokine hypothesis of overtraining: a physiological adaptation to excessive stress? Med Sci Sport Exercise. 2000;32:317-31.

111. Pedersen BK, Ullum H. NK cell response to physical activity: possible mechanisms of action. Med Sci Sports Exerc. 1994:26:140-6.

112. BaughmanShively S, Szakaly-Horkayne I, Jones RV, Kelly JP, Armstrong RC, Perl DP. Characterisation of interface astroglial scarring in the human brain after blast exposure: a post-mortem case series. Lancet Neurol. 2016. doi:10.1016/S1474-4422(16)30057-6.
113. Stein MB, McCallister TW. Exploring the convergence of posttraumatics stress disorder and mild traumatic brain injury. Am J Psychiatry. 2009;166:768-76.

114. Bryant RA. Disentangling mild traumatic brain injury and stress reactions. N Engl J Med. 2008;358:526-7.

115. Kulka RA, Schlenger WE, Fairbank JA, Hough RL, Jordan BK, Marmar CR, Weiss DS. Trauma and the Vietnam war generation: report of findings from the National Vietnam veterans readjustment study. New York: Brunner/Mazel; 1990

116. Pitman RK, Altman B, Macklin ML. Prevalence of post-traumatic stress disorder in wounded Vietnam Veteran. Am J Psychiatry. 1989;146:667-9.

117. Llompart-Pou JA, Raurich JM, Perez-Barcena J, Barcelo A, Ibanez J, Avestaran Jl. Acute hypothalamic-pituitary-adrenal response in traumatic brain injury with and without extracerebral trauma. Neurocrit Care. 2008:9:230-6.

118. Nijm J, Johasson L. Inflammation and cortisol response in coronary artery disease. Ann Med. 2007;41:224-33.

119. Laurent HK, Lucas T, Pierce J, Goetz S, Granger DA. Coordination of cortisol response to social evaluative threat with autonomic and inflammatory responses is moderated by stress appraisals and affect. Biol Psychol. 2016;118:17-24.

120. Taylor MK, Reis JP, Sausen KP, Adilla GA, Markham AE, Potterat EG, Drummone SPA. Trait anxiety and salivary cortisol during free living and military stress. Aviat Space Environ Med. 2008;79:129-35.

121. Lerman SE, Eskin E, Flower DJ, George EC, Gerson B, Hartenbaum N, Hursh SR, Moore-Ede M. ACOEM guidance statement. fatigue risk management in the workplace. J Occup Environ Med. 2012;54:231-58.

122. Buchheit M. Monitoring training status with HR measures: do all roads lead to Rome. Front Physiol. 2014:5:73.

123. Schmitt L, Regnard J, Millet GP. Monitoring fatigue status with hrv measures in elite athletes: an avenue beyond RMSSD. Front Physiol. 2015;6:343.

124. Elsner KL, Kolkhorst FW. Metabolic demands of simulated firefighting tasks. Ergonomics. 2008;51:1418-25.

125. Tofari PJ, Laing Treloar AK, Silk AJ. A quantification of the physiological demands of the army emergency responder in the Australian army. Mil Med. 2013:178:487-94.

126. Kuehl KS, Kisbu-Sakarya Y, Elliot DL, Moe EL, DeFrancesco CA, MacKinnon DP, Lockhart G, Goldberg L, Kuehl HE. Body mass index as a predictor of firefighter injury and workers' compensation claims. J Occup Environ Med. 2012;54:579.

127. Dobson M, Choi B, Schnall PL, Wigger E, Garcia Rivas J, Israel L, Baker DB. Exploring occupational and health behavioral causes of firefighter obesity: a qualitative study. Am J Ind Med. 2013:56:776-90.

128. Poston WSC, Haddock CK, Jahnke SA, Jitnarin N, Tuley BC, Kales SN. The prevalence of overweight, obesity, and substandard fitness in a population-based firefighter cohort. J Occup Environ Med. 2011;53:266.

129. Walker A, Driller M, Argus C, Cooke J, Rattray B. The ageing Australian firefighter: an argument for age based recruitment and fitness standards for urban fire services. Ergonomics. 2014;57:612-21.

130. Mora-Rodriguez R. Influence of aerobic fitness on thermoregulation during exercise in the heat. Exerc Sport Sci Rev. 2012;40:79-87.

131. Wallace RF, Kriebel D, Punnett L, Wegman DH, Wenger CB, Garner J, Kark J. Risk factors for recruit exertional heat illness by gender and training period. Aviat Space Environ Med. 2006;77:415-21.

132. Jay SM, Sprajcer M, Aisbett B, Ferguson SA. Sleeping at work: its not all about location, location, location. Sleep Med Rev. 2015;19:59-66.

133. Lamond N, Jay SM, Dorrian J, Ferguson SA, Jones CB, Dawson D. The dynamics of neurobehavioural recovery following sleep loss. J Sleep Res. 2007;161:33-41.

134. Van Dongen HPA, Belenky G, Vila BJ. The efficacy of a restart break for recycling with optimal performance depends critically on circadian timing. Sleep. 2011;34:917-29.

135. Pejovic S, Basta M, Vgontzas AN, Kritikou I, Shaffer ML, Tasoussoglou M, Chrousos GP. Effects of recovery sleep after one work week of mild sleep restriction on interleukin- 6 and cortisol secretion and daytime sleepiness and performance. Am J Physiol Endocrinol Metab. 2013;305:E890-6. 